\title{
Discussion on Some Enlightenment from Construction Characteristics in Berlin
}

\author{
Shang Zhen \\ School of Design Art, Harbin University of Commerce, Harbin 150028, China
}

Keywords: Berlin, city, construction, politics, spirit.

\begin{abstract}
There must be a lot of things are worthy of our learning and thinking in cities like Berlin. Berlin's urban construction characteristics are distinctive: first, this city attaches great importance to the repair and maintenance of ancient buildings; second, there are still a lot of 1960s and the 1970s' old buildings of modernist period in this city; third, the new buildings and the old buildings are symbiotic, the project construction amounts of single street are comparatively small. If we understand the construction characteristics of Berlin in detail, we can easily get a deeper level of thoughtful connotation.
\end{abstract}

\section{Introduction}

Berlin as an imperial city, a city that has gone astray but does not sink; a scarred but still proud city; a city once were beheaded but miraculously revived, it is like a child through suffering in boyhood, overcome the thousands of difficulties, and gradually become mature. Such a child must have a story, this city must have a lot of things worth our study and thought.

\section{Characteristics of Urban Construction of Berlin}

The feelings that Berlin bring are often different from those who first arrived here, clean and tidy streets, elegant and chilly Berlin Brandenburger Gate, holy and solemn World War II monument with military hardware (see Fig.1), the bullet holes of old building are inevitable to bring people's thoughts back to the precarious war years at the beginning of the last century. The modernist crash board building and occasional doodle wall the 1960s and the 1970s (see Fig.2), and let people feel the sorrow in silence year after year. But when we watch the new building in the city, we will see the hale sight of this city. Berlin's urban construction characteristics are distinctive:

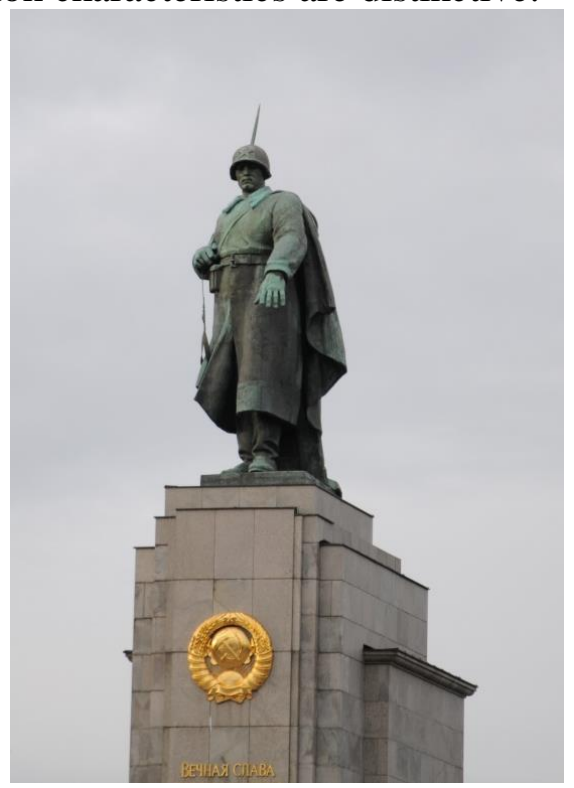

Fig.1 Monument of Soviet army 
First, this city attaches great importance to the repair and maintenance of ancient buildings. The destroyed buildings in the war are almost recovered brick by brick, and there are distinctions between the new repair part and the original material of the old building, differentiation degrees are higher. The surface scars of buildings caused by the war are basically preserved. The bullet holes, the cannon pit and the smoke marks are clearly visible in the building, like the plaintive dirge; tell the melancholy of war (see Fig.3). This serious attitude is also reflected in repair and recreation of the interior decoration. "The restorations of original appearance like the old, the maintenances are delicate, new works are simple and concise" can be used to summarize (see Fig.4).

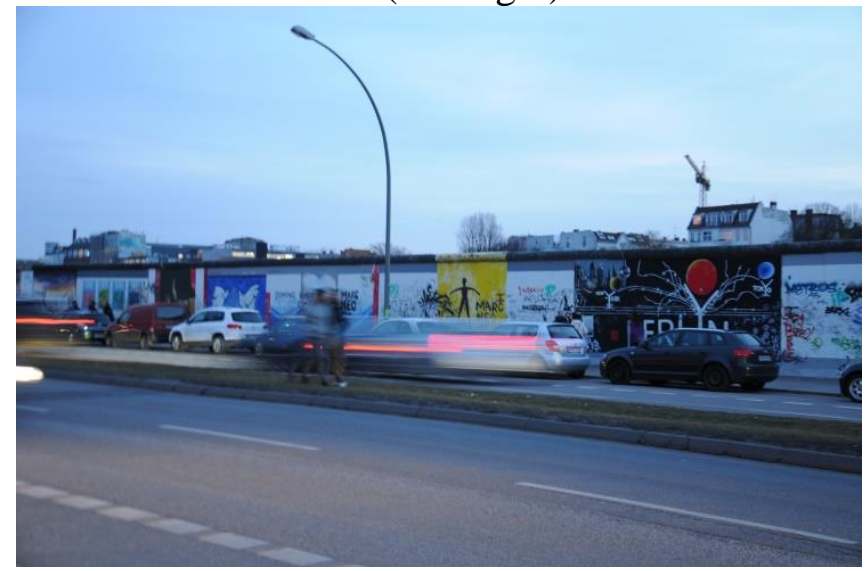

Fig.2 The residual wall of Berlin wall, one of the birthplaces of graffiti art

Second, there are still many old modernist buildings in the 1960s and the 1970s (see Fig.5). Although these building are still neat as new, full of decoration, the given overall feeling is still the old era. Such urban landscape is difficult to find in equivalent city in China. It is hard to imagine that the capital of the country on the European continent's top economy would have deliberately retained the old time, rather than entirely remove "obsolete product" as our city.

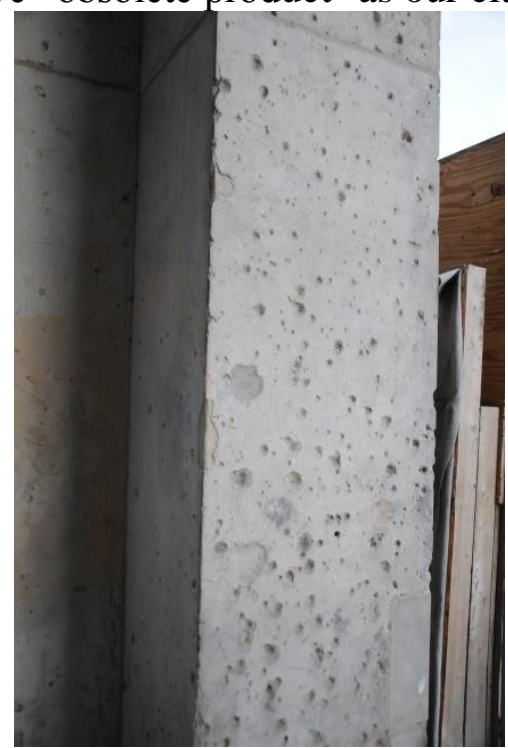

Fig. 3 The ubiquitous war traces in Berlin

Another consequent event of this city characteristic is that indirectly causes the most classic paintings of Berlin's visual artists are not on the shelf, but on the walls of their city buildings. In Europe, painting art is regarded as a very elegant art. Few city painters have positioned themselves as street artists, and their works are often put on the shelf in the most famous museums. But Berlin is different. The essences of Berlin painting art are reflected graffiti in the big streets and small alleys, with the vicissitudes and once the young miss. The Berlin artists seem to no high-class as other city artists', and their art is approachable. The initial reason may be because the canvas they once had - the Berlin Wall is too hard and ruthless, so they would use the glory of human nature to wrap the exclamatory wall, but now, their work became the city's essential public art. The commonplace appearances of internationalist "affordable housing" are elegant by their elaborate decoration. 


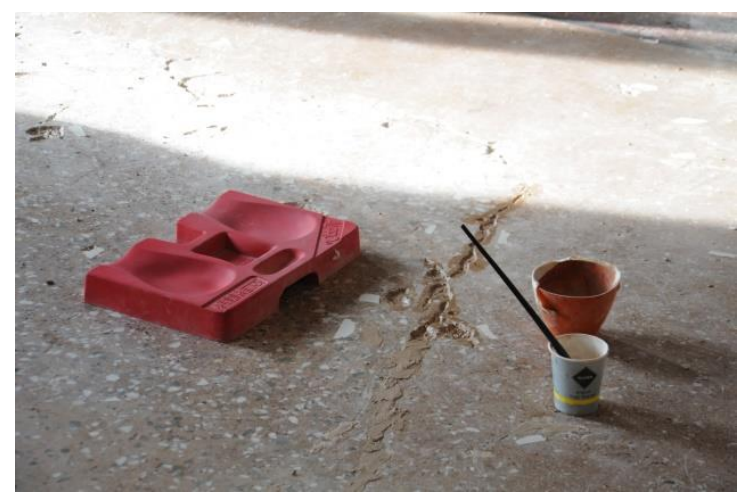

Fig. 4 Interior restoration of Berlin building

Third, the new buildings and the old buildings are symbiotic; project construction amounts of a street are smaller. Berlin's urban construction is connotative development. Here you cannot see the drastic urban construction scene. But there are always some small amounts of new style building together with the building in 1960s and the 1970s in each street, and even the building in 1930s and the 1940s. There are a few building sites in the construction in each street. But if we look from the height, we will find that the total construction amounts of Berlin are not small, but they are equally distributed to each street (see Fig.6). In addition, the author through several bird's-eye views that people shot in the top of the Berlin cathedral from 1995 to 2013, the comparison found that the construction amounts of Berlin are almost no major changes over the years. The result of this practice is that the change processes of urban landscape are slow, but always maintain a sustained, normal development.

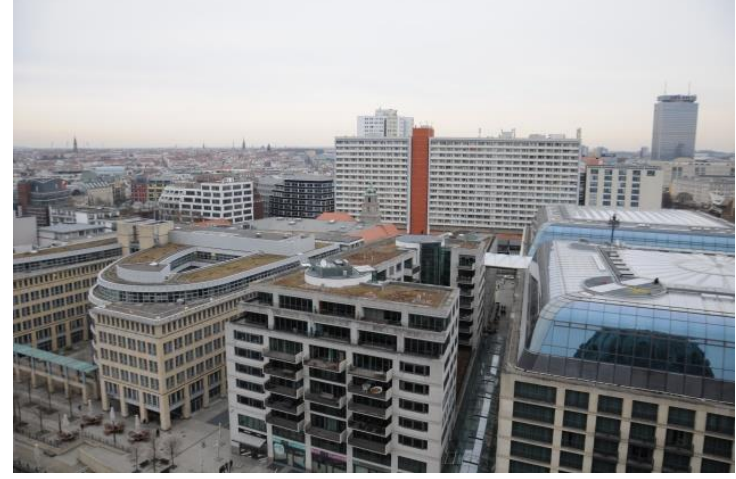

Fig.5 Ubiquitous modernist building

If we understand the construction characteristics of Berlin, we can easily get a deeper level of thoughtful connotation. There are a lot of things worth our learning.

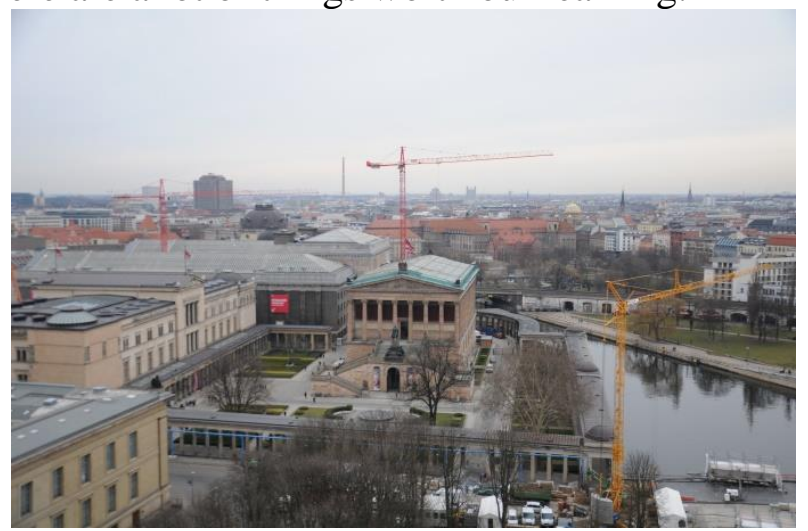

Fig.6 Routine construction updates work in Berlin from the last century to now

\section{Deep connotations of the urban construction characteristics in Berlin}

\subsection{Old building value of the city}

Generally speaking, the choices of what kind of city demolition-construction mode and scale are actually determined by our value assessment of old buildings. The core of the evaluation of the old 
buildings value is to measure economic value. In general, high scarcities of these buildings; the poor practicability, low housing demand, these characteristics determine the relative depreciation of their economic value. So our approach is to choose to dismantle and reconstruct in most cases. But from the attitude Berlin's people treat the old building; we can deeply realize that the economic values are certainly not all the values of the old building. Through the research and visit of Berlin, we can easily find the some accessary values of old buildings:

The first is the context value. The time is irreversible, the past cannot be repeated, and to witness the past story is only the relics of the times. So the old building will contain a lot of information that belongs to that era. Life has never stopped; this information remains connected with the past. And the changes in customs and culture will make the existence of the old buildings in today's building differences and reference features. Taking Berlin City for example, where we found the repaired ancient buildings and 1930s and the 1940s' buildings, 1960s and the 1970s' international style of building, 1980s and the 1990s' building and building in recent years are placed in the marketplace; we can deeply understand the endless cultural heritage of buildings.

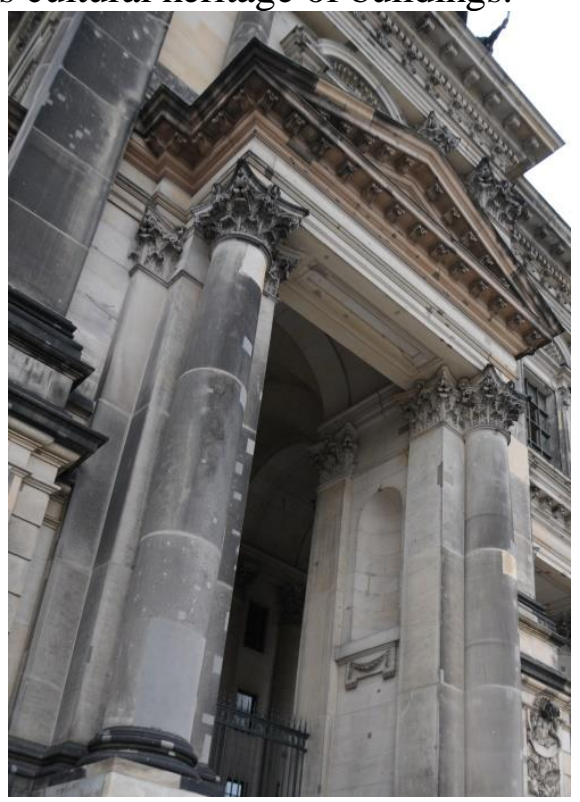

Fig.7 The attitude guidance significance of the German government to the war damage repair of building is particularly prominent

The second is the place value. No matter who has an identity sense for some scenes? It is as if with the increase age, we will miss the childhood environment, whether it is good, bad, luxurious or simple. This identity sense of the scene is interwoven with time and stories, which is the point of people's minds; whether the existence of such an environment or not cannot be measured by the economic value for people' psychological impact. This point which West Berlin does is obviously better than East Berlin.

The third is aesthetic value. The diversity of building and the environment will add more charm to the city. If you think about this problem from the perspective of tourism, then this point can be linked with the economy. At least in Berlin, we can feel the beauty of the international style building that we never realized before. From Berlin artists' combining the outdoor graffiti with the old building, we can realize that the existence itself of old buildings provides the media and more possibilities for new forms of artistic expression. 


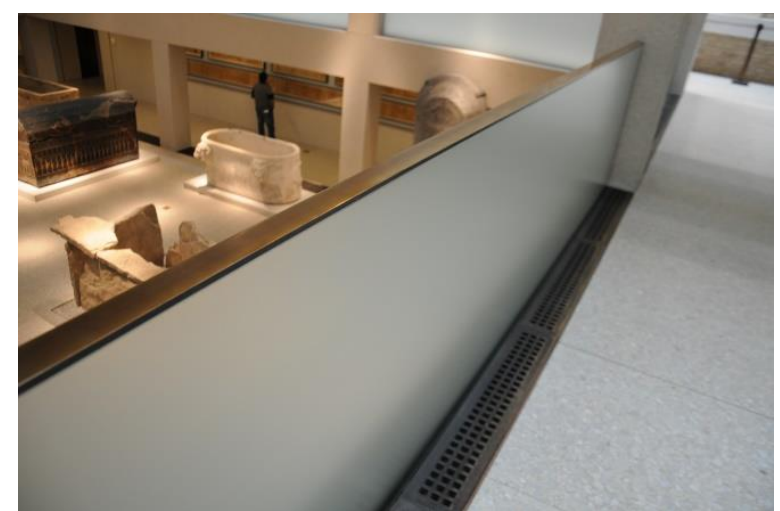

Fig. 8 The plain attitude faces history is to reflect an important world outlook guidance value as well

The fourth is the value of resources. From the point of view of resource protection and avoidance of waste, the use of a building is stronger than being replaced. This is another main reason that Berlin retains a lot of buildings with international style.

The last is the guidance value (see Fig.7, Fig.8). The attitude that a city or even a country's government treats old buildings actually can reflect the attitude of the government' economy, culture and art, and even reflect the character of the nation. From this point of view, the implicated guidance information value of demolition-rebuilding of an old building is even higher than the economic value. In Berlin, we can clearly feel this value-oriented deep meaning; this point will be further elaborated in below.

\subsection{The renovation measures for old buildings}

The old buildings will be out of date one day in theory, so will be remedied or rebuilt someday. The renovation is more complicated than rebuilding. It should be adjusted for the "outdated" part of building. The obsoleteness here includes the material structure, function, image, regional environment, policy, assets and other aspects of the buildings. So it is difficult to remedy. The main problems include the complexity of the historical problems of the old buildings; the actual value is difficult to determine accurately; the cost of demolition is higher than alternative; it is difficult to estimate accurately the long-term value. In addition, as mentioned above, from the perspective of attached value of urban architecture, the overall image of city and resource utilization, the large-scale renovation or redevelopment is obviously one of the most undesirable practices. Thus, it can be seen that the selecting remediation measures, methods and time is crucial adapted to environment. If this matter is refined to a concrete blocks, so different buildings in this street are made local regulation or different level of demolishment, or direct rebuilding, it is necessary to further investigation and precise argument. Each building should be formulate the corresponding retrofit scheme from the view of the whole street, determine which buildings should be in what time to what kind of way to reconstruct, what kind of speed upgrade in whole streets every year. In this regard, the city planning and construction department of Berlin is much more elaborate and rigorous than we do. Their work is based on the development of the construction of the greatest potential value of the premise, not one-sided for GDP growth and economic benefits and other reasons should not do the decision. So we see that Berlin's urban construction has never been done as a once and for all thing, and the work is done in an orderly manner at all times, and the city's landscape is changing slowly. Such a way to save resources and scientific and reasonable way of urban construction is worthy our learning. 


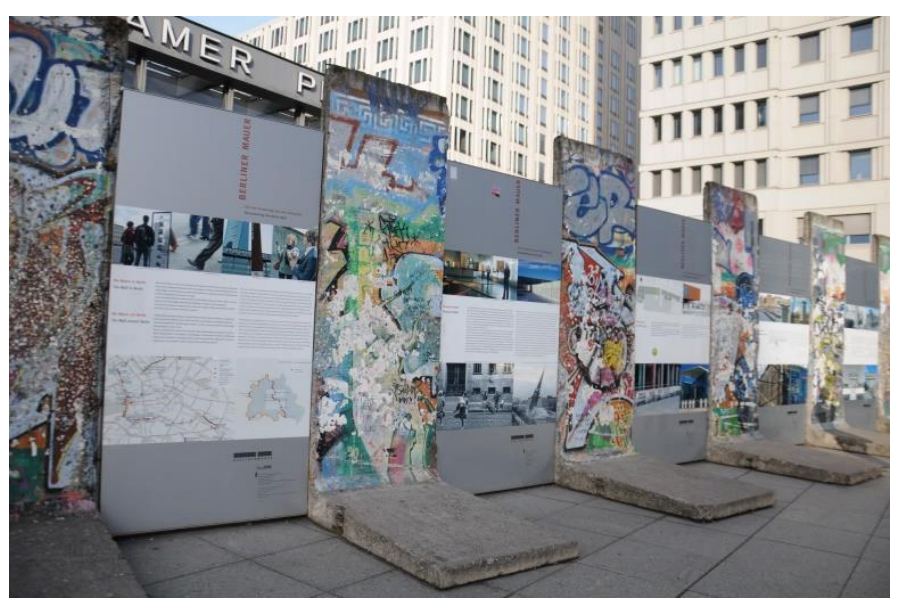

Fig.9 Berlin's graffiti wall in the application of urban landscape construction

\subsection{Expression way combined art with urban construction}

Berlin's urban graffiti provides us with a new perspective at least in the applied value of painting art (see Fig.9). As mentioned above, due to special historical reasons, the Berlin's painters prefer a distinctive painting art form-street graffiti art. The Berlin are very different from other cities is that the city's street graffiti show a remarkably high level. And this graffiti art has been blended with the urban construction of Berlin. This is a matter of greatly opening up one's eyes, so we can deduce that the construction of the city can take a more diversified art form, the city's construction is not only the city planning department and the mayor's things, as urban construction work under postmodernist concept, but also should attract the enthusiasm of all the people. Of course, this is not to say that our urban construction must allow vulgar pictures or more outrageous other acts, and the public's eclectic urban landscaping and building passion should be ignited under the effective control and guidance of the government. The government may do something in the corresponding policies and regulations.

\section{Urban Construction of Berlin Reflects the Spirit of the Public}

It is generally known that Germany's attitude towards history is sincere. We can deeply feel from the repair and protection of its urban construction and old buildings. Mottled stone, the walls that covered with holes, all reflect the attitude that Berlin people dare to face the scars, have the courage to admit mistakes and diligent to create a better future. Of course, our people also have excellent quality; our country is also recognized by the world in the industrious and brave aspect. However, I saw the German people are more worthy of our study in the urban construction of Berlin. One of the most important points is the steady mentality. In our country, more than a hundred years of humiliation and repression make us aspire to make our country more prosperous than any time before, are eager to achieve the great rejuvenation of the Chinese nation. So our city in the past four decades of construction process, it is inevitable to advance too quickly. Some utilitarian urban construction methods and rough urban construction remediation means make China's urban construction in achieving high efficiency results also caused a lot of waste of resources, and the urban personality rapidly disappear, the environment suffer irreversible damage and other serious problems. Put aside the relevant personnel' malfeasance and decision-making mistakes, the whole social impetuous psychology problem does exist in our country's urban development and construction process from a macro perspective. As the saying goes, "a watched pot never boils", the desire that we build the motherland and improve the city life is good, but if you can't with scientific and rigorous attitude to do it, "great leap forward" consequences will follow, this is worth our vigilance. Fortunately, our country has recognized the problem, now consciously slows the speed of economic development, and has set a more harmonious and scientific development concept. Whether we should also make corresponding change in our urban planning and construction work specifically?

The next is the transitional attitude of urban construction. We should realize that the urban construction is a relatively long historical process, which is by no means leadership' work overnight, 
the obtained construction achievements cannot be obliterated by which new deal, new situation and new method, no matter how it is there, that is our past, not someone else, there is not only a failure, there are more worthy of our inheritance. Berlin provides a good example for us in this aspect, we don't see "when a man expires his work will stop" dilemma and blind denial of our predecessors, all are orderly and successive.

In contrast to our urban construction attitude, it seems less respect for the work of predecessors. The city's development strategy tends to change with the change of the person in charge, and the general public is often eager to more than ten years ago or even a few years ago the building characterization outdated, we hear is how the past is how bad, how correct. We only focus on the protection of the remote history, but never thought too close to the history of the need to be selectively retained. The city of Berlin and the perfect combination of art in the sixties and seventies architecture provides us with a classic example, when we look back on the road, at least we walked along the footprints should be continuous. In contrast, our urban constructions seem to be less respect for the work of predecessors. The development strategies of city tend to change as the alternation of principal, ordinary citizens are often eager to regard buildings more than ten years ago even a few years ago as obsolete, what we hear is always how bad in the past, how right now. We only pay attention to the protection of the remote history, but never think about the near history is also need to be selectively preserved. The 1960s and 1970s' building perfectly combined art in Berlin, which provides a classic example for us, when we look back on the past, at least, the footprints that we have walked should be continuous.

\section{Summary}

The above is a little author's thinking for the building characteristics of Berlin. When we jump out of our own circle and compare different environments from another angle, it is easy to find our own advantages and disadvantages. In fact, our urban construction has been a world leader in many aspects. For instance, the solution of traffic problems, and many cites cannot do as excellent as China in many countries all over the world. But as mentioned above, we have some defects in some aspects compared with cities in other countries. In order to prevent many detours in the urban construction, after a period of striding forward, we should calm down and look around, more compared with cities in other countries, we adjust based on not blindly denying the original route, our road will go off smoothly only in this way. It is also the best annotation to eliminate blundering and transitional spirit as mentioned above.

\section{References}

[1]. Liu Baoguo: the Protection of Historical and Cultural Blocks, China Architecture \& Building Press. 2013.

[2]. Huang Yong, Shi Yaling: The Updated Planning and Practice Review of Historical Block Protection at Home and Abroad, Planners, 2015.04.

[3]. Liang Qiao, Liang Hua: Profound Consideration on the Current Situation of Historical Blocks in China, Chinese \& Overseas Architecture, 2016.01.

[4]. Wang Zhenzhe: Modernity of Historical and Cultural Blocks, Guangxi Normal University Press, 2015.07.

[5]. Shan Jixiang: The Protection of Historical and Cultural Blocks, Tianjin University Press, 2015.06. 